\title{
Development and Validation of a Stability-indicating HPLC Technique for Measuring Temozolomide in its pharmaceutical dose form
}

\author{
NARAYAN SHRIVAS ${ }^{1 *}$ and S. K. MISHRA² \\ ${ }^{1}$ Research Scholar, Department of Chemistry, Jiwaji University Gwalior (M.P.), 474001, India. \\ 2Department of Chemistry, Government P. G. College, Datia (M.P.), 475661, India. \\ ${ }^{\star}$ Corresponding author E-mail: ndmica@gmail.com \\ http://dx.doi.org/10.13005/ojc/370418
}

(Received: June 24, 2021; Accepted: August 20, 2021)

\begin{abstract}
Using RP-HPLC, an accurate and precise technique for the measurement of Temozolomide in its pharmaceutical dose form was developed and validated. Chromatographic separation was achieved on an X Terra RP $18(250 \mathrm{~mm} \times 4.6 \mathrm{~mm}), 5 \mu$ column using a mobile phase consisting of methanol and buffer in the ratio of $10: 990 \mathrm{v} / \mathrm{v}$. The flow rate was $1 \mathrm{~mL} / \mathrm{min}$ with the detection wavelength of $254 \mathrm{~nm}$ and retention time was found to be 20 minute. The developed method was validated according to $\mathrm{ICH}$ guidelines. With a correlation coefficient of 0.9990 , linearity was observed in the range of 50-150 percent. The \%RSD of the developed method for precision and Intermediate precision was found to be $0.65 \%$ and $0.59 \%$ respectively. With a percent recovery of $99.82 \pm 0.045$, the approach was confirmed to be reliable. All of the validation parameters yielded results that were within acceptable limits. It was discovered that the procedure was accurate, exact, specific, rugged, and durable. As a result, the newly discovered approach can be used for finish product of quality control and stability testing on a regular basis and it has been confirmed to be stable for Temozolomide is available in both pure and pharmaceutical dose forms.
\end{abstract}

Keywords: RP-HPLC, Temozolomide capsules, Method development, Validation and Method Stability indicating.

\section{INTRODUCTION}

Imidazotetrazine derivative of temozolomide. The chemical name of Temozolomide is 3,4-dihydro3-methyl-4-oxoimidazo[5,1-d]-as-tetrazine-8carboxamide ${ }^{1}$. Temozolomide is an anticancer agent that is used to treat Grade IV astrocytoma, a type of aggressive brain tumor also known as glioblastoma multiforme, and skin cancer ${ }^{2}$. Temozolomide inhibits DNA replication and so has antineoplastic action that is time-dependent. Temozolomide sold under the brand name Temodar and is taken by mouth or via intravenous infusion ${ }^{3}$.<smiles>Cn1nnc2c(C(N)=O)ncn2c1=O</smiles>

Fig. 1. Structure of Temozolomide

This is an Open Access article licensed under a Creative Commons license: Attribution 4.0 International (CC- BY). Published by Oriental Scientific Publishing Company @ 2018 
Temozolomide is available as a capsule or as an injectable powder. It is available in the pharmaceutical market for the effective treatment of different types of cancer. Temozolomide is a drug that comes in both bulk and pharmaceutical dosage forms.

As a result, drug quality testing is critical in the pharmaceutical industry. The branch of chemistry dealing with the separation, identification, and determination of compounds is known as analytical chemistry. The proportions of the constituents that make up a sample of matter. It is mostly used for qualitative compound identification or detection, as well as quantitative assessment of components present in bulk and medicinal formulations ${ }^{4}$.

A review of the literature for temozolomide analysis indicated that there are multiple extant methods for temozolomide analysis, including several techniques such as spectrophotometric ${ }^{5}$, HPLC $^{6}$, colorimetric ${ }^{7}$, LC/MS $^{8}$ and UPLC ${ }^{9}$ methods for the determination of Temozolomide in single dosage form and HPLC ${ }^{10}$. The purpose of this research was to create and test a new HPLC method for estimating Temozolomide that was simple, precise, economical, cost-effective, and took less time. The proposed HPLC method's major application is to figure out how much medication is in commercial formulations. The newly designed approach was verified in accordance with the International Conference on Harmonization $(\mathrm{ICH})$ criteria. Validation of system appropriateness, linearity, precision, accuracy, specificity, ruggedness and robustness, detection limit, and limit of quantification ${ }^{11,12}$.

\section{MATERIAL AND METHOD}

\section{Reagents and Chemicals}

Choksi Lab Indore (MP) Marketed Capsule formulation NATCO Pharma Ltd provided. As a sample of donations, Temozolomide (purity: 99.8\%). A local drugstore sold a tablet containing 20 milligrams of TMZ. Merck India supplied the HPLC-grade methanol and water. Other solvents used were analytical grade, glacial acetic acid and ammonium format.

\section{Instrument and Analytical conditions}

Waters alliance HPLC 2996 with a Waters photodiode array detector and UV-Vis detector 2487 was used for the analysis. The chromatographic separation was performed in X terra RP18, (250mm $x 4.6 \mathrm{~mm}$ ), $5 \mu$ (Waters, Ireland). The mobile phase consisted of buffer and methanol (contain $0.4 \mathrm{~g}$ of ammonium format into $1000 \mathrm{~mL}$ volumetric flask). The newly prepared mobile phase was filtered using $0.20 \mu \mathrm{m}$ nylon membrane filter pore size and pumped with a flow rate of $1.0 \mathrm{~mL} / \mathrm{min}$ in isocratic mode. The analyte elution was monitored at $245 \mathrm{~nm}$ wavelength

\section{Preparation of Mobile phase Buffer}

Transfer $0.4 \mathrm{~g}$ of ammonium format in to $1000 \mathrm{~mL}$ volumetric flask and dilute up to mark with water and mix well.

Prepare mixture of buffer: methanol in the ratio of $990: 10$. Filter and degas prior to use. (Use before $72 \mathrm{~h}$ after preparation).

\section{Preparation of Diluent}

Use mixture of 0.1 percent $(v / v)$ of glacial acetic acid solution, prepared in water

\section{Preparation of Standard}

Transfer about $25 \mathrm{mg}$ of Temozolomide WRS precisely weighed in a $25 \mathrm{~mL}$ volumetric flask. Dissolve and dilute up to the mark. Dilute $5 \mathrm{~mL}$ to $100 \mathrm{mLdiluent}$ of this solution. Temozolomide (50 ppm).

\section{Preparation of Sample}

Weigh and report the weight of 20 undamaged capsules (W1). Empty the contents of the capsules into an appropriate container as fully as possible. Remove the contents from the interior of each capsule shell with a cotton swab. Weigh 20 empty pill shells precisely (W2). Calculate the average capsule fill weight. Weigh and transfer a part of the capsule blend, equal to roughly $25 \mathrm{mg}$ of Temozolomide, to a $25 \mathrm{~mL}$ volumetric flask with precision. Add about $10 \mathrm{~mL}$ of diluent and sonicate for about 10 min shaking occasionally. Allow to cool to ambient temperature before diluting to volume with diluent. Centrifuge the resultant solution for $10 \mathrm{~min}$ at $3000 \mathrm{RPM}$. Further dilute $5 \mathrm{~mL}$ of this solution to $100 \mathrm{~mL}$ volumetric flask and dilute up to the mark with diluent. 


\section{Method validation}

The technique was verified in accordance with $\mathrm{ICH}$ standards ${ }^{13}$. All of the qualities of accuracy, precision, linearity, specificity, ruggedness, robustness, and stability were confirmed. Degradation experiments were also carried out by exposing Acidic, basic, peroxide, thermal, neutral, and photolytic conditions are all used to test the drug's solution.

\section{RESULTS AND DISCUSSION}

Several mobile phase ratios at varying flow rates were initially explored to elute the medications in order to develop the method. Based on peak parameters, the mobile phase was chosen to be a combination of buffer $(0.4 \mathrm{~g}$ ammonium format into $1000 \mathrm{~mL}$ volumetric flask): methanol in the ratio of $990: 10 \mathrm{v} / \mathrm{v}$ at $1.0 \mathrm{ml} / \mathrm{min}$ in Revers phase isocratic mode. The medicines were separated using a Discovery RP $18,(250 \times 4.6) \mathrm{mm}, 5)$ column. The temperature in the column oven was kept at 25 degrees Celsius. The wavelength of $254 \mathrm{~nm}$ was identified as the most suitable for drug monitoring. The chromatographic system was injected with the prepared standard and sample solutions, and the system suitability and percent assay were determined. The chromatograms of the standard, and sample were depicted in Figs. 2, and 3, respectively.

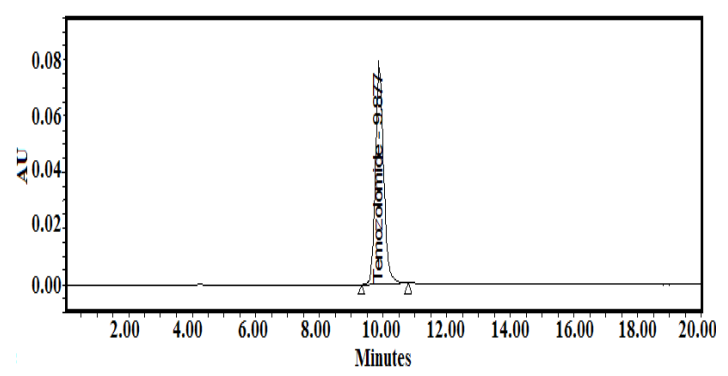

Fig. 2. Standard chromatogram

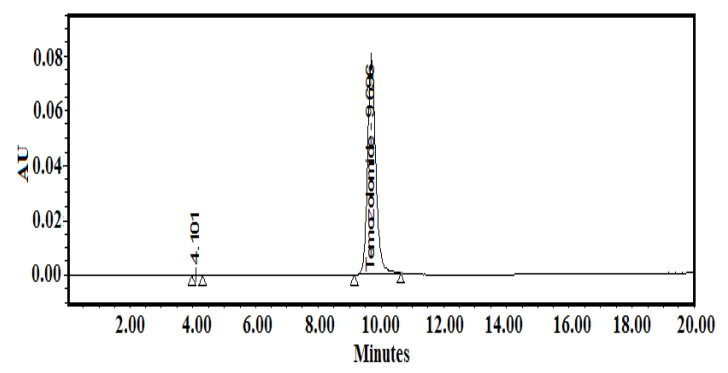

Fig. 3. Sample as Such
The validation parameters were used to validate the created technique. To verify the method's linearity, dilutions of the standard solution in the concentration range of $50 \mathrm{~g} / \mathrm{mL}-150 \mathrm{~g} / \mathrm{mL}$ for Temozolomide were prepared. Peak areas and concentrations for Temozolomide pharmaceuticals were displayed on a graph, and the correlation coefficient was determined to be 0.9990 , suggesting that the technique follows Beer's law. Fig. 4 shows the linearity charts.

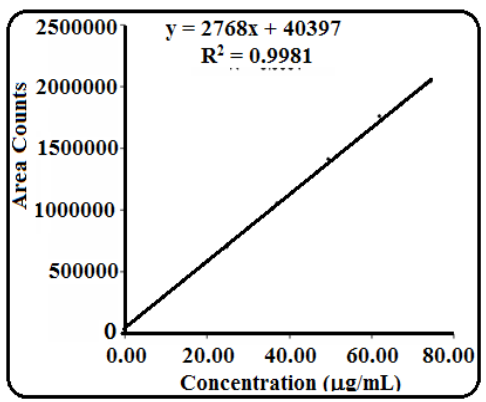

Fig. 4. Linearity of response

Table 1: Results of system suitability and validation parameter

\begin{tabular}{lc}
\hline Parameters & Temozolomide \\
\hline Specificity & Specific \\
Precision (\% RSD) & 0.65 \\
Accuracy (\% Recovery) & $50 \%$ to150\% \\
Linearity range $(\mu \mathrm{g} / \mathrm{ml})$ & $25-75$ \\
Correlation coefficient $(\mathrm{r})$ & 0.9990 \\
Method Robustness & Robust method \\
Method Stability & Stable method \\
Tailing factor & 1.15 \\
Plate count & 7036 \\
\hline
\end{tabular}

The RSD percentage variation was determined to be 0.38 for Temozolomide, indicating that the technique is accurate. The percentage recovery was 98.0 percent-100.2 percent for Temozolomide, which showed that the technique was correct. The approach was determined to be specific since excipients do not interfere with the drug's retention period. The technique was discovered to be tough and reliable. To test the stability of the medicines, the standard pharmaceuticals were exposed to forced deterioration conditions. The medicines were determined to be stable since their degradation was within the net degradation limits under various stress situations. Table 2 and Fig. 5 show the findings of the forced deterioration research as well as the chromatograms. 
Table 2: Result of Forced degradation studies

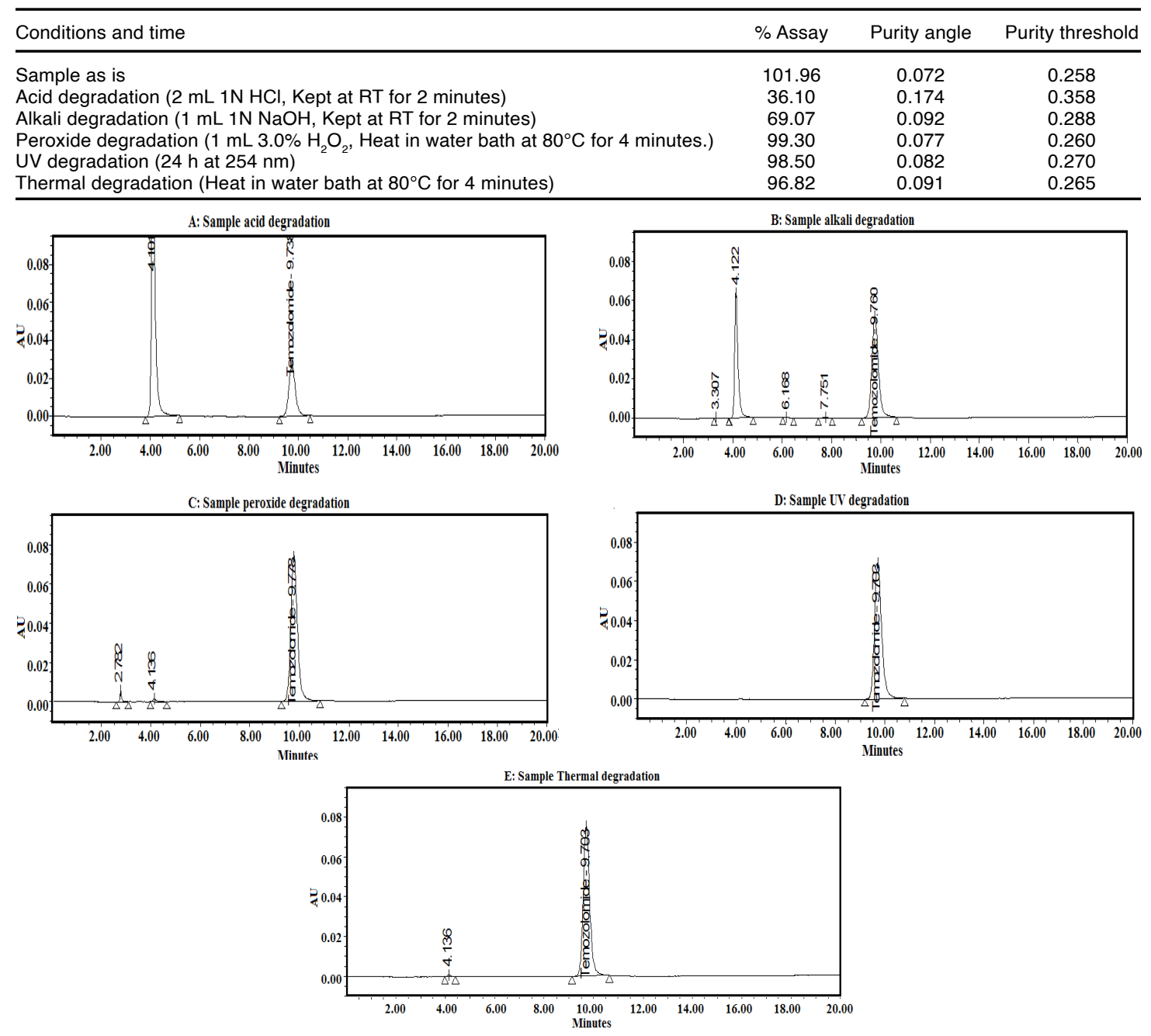

Fig 5: Specificity of methods

\section{CONCLUSION}

Using RP-HPLC, a stability indicating technique for Temozolomide determination in Temozolomide capsule's dosage form was established. The verified technique was accurate, exact, specific, linear, rugged, robust and stable. The medicines were shown to be stable under forced degradation circumstances, according to the results of the research. This technique is suitable for determining

Temozolomide in its dose form for routine analysis.

\section{ACKNOWLEDGMENT}

The authors would like to thank Choksi Lab Indore MP, (India) for supplying the drug samples as well as the facilities to conduct the research.

\section{Conflict of Interest}

The author declares that there is no conflict of interest.

\section{REFERENCES}

1. A. Abdul Razak.; SK Masthanamma.; B. Omshanthi.; V. Suresh, P. O. Int. J. Pharm Tech Res., 2013, 4(4), 1419-1423.

2. B. Mohammed, I.; Hindustan, A. A.; Shaik, M.;
S., P.; B., F. Int. Res. J. Pharm., 2014, 5(1), 17-20.

3. Parle, V. Int. J. Pharm. Sci. Res., 2016, 7(3), 1298-1301. 
4. Chourasiya, P.; Roy, R. K.; Karole, S.; Diwakar, S.; Jain, P. Asian J. Pharm. Educ. Res., 2020, 9(3), 33-41.

5. Mishra, A. K.; Rajdhar Yadava, Amrita Mishra, Anurag Verma, P. C. Int. J. Pharma Res. Dev., 2010, 6, 2-6.

6. Khan, A.; Imam, S. S.; Aqil, M.; Sultana, Y.; Ali, A.; Khan, K. Beni-Suef Univ. J. Basic Appl. Sci., 2016, 5(4), 402-408.

7. Rizwana, I.; Vanitha Prakash, K.; Krishna Mohan, G. Int. J. Pharm. Pharm. Sci., 2014, 6(6), 532-535.

8. Saravanan, G.; Ravikumar, M.; Jadhav, M.
J.; Suryanarayana, M. V.; Someswararao, N.; Acharyulu, P. V. R. Chromatographia., 2007, 66(3-4), 291-294.

9. Ilham, R. Asian J. Chem., 2018, 26(12), 70-73.

10. Online, I. N. Int. J. Theor. Appl. Sci., 2012, 4(2), 48-55.

11. Harron, D. W. G. Textb. Pharm. Med., 2013, 1994, 447-460.

12. Kumar, A.; Kishore, L.; Kaur, N.; Nair, A. Chronicles Young Sci., 2012, 3(1), 3.

13. Bhardwaj, S. K.; Dwivedi, K.; Agarwal, D. D.; Analytical, S., 2015, 5(4), 76-81. 